This chapter describes the history of the Eccles et al. Expectancy Value Model and research on the influence of social and psychological factors on gender and ethnic differences in math, science, and information technology choices.

\title{
Studying Gender and Ethnic Differences in Participation in Math, Physical Science, and Information Technology
}

\author{
Jacquelynne S. Eccles
}

Over the past thirty years, my colleagues and I have studied the psychological and social factors influencing course enrollment decisions, college major selection, and career aspirations, as well as other achievement-related activity choices. We began this work with a particular interest in the psychological and social factors that might underlie gender differences in educational and vocational choices, particularly in the fields of mathematics, physical science, and engineering. Frustrated with the many disconnected theories emerging to explain such gender differences, we developed a comprehensive theoretical model of achievement-related choices to guide our subsequent research efforts (Eccles [Parsons] and others, 1983; see Figure 2.1 for the most recent version). Drawing on work associated with decision making, achievement theory, and attribution theory, we hypothesized that educational, vocational, and avocational choices would be most directly related to individuals' expectations for success and the importance or value they attach to the options they see as available. We also outlined the relation of these beliefs to cultural norms, experiences, and aptitudes and to those personal beliefs and attitudes that are commonly assumed to be associated with achievement-related activities (see Eccles [Parsons] and others, 1983; Eccles, 1987; Eccles, Wigfield, and Schiefele, 1998).

For example, consider decisions related to college major. Based on our work, we predict that people will be most likely to choose a major that they 


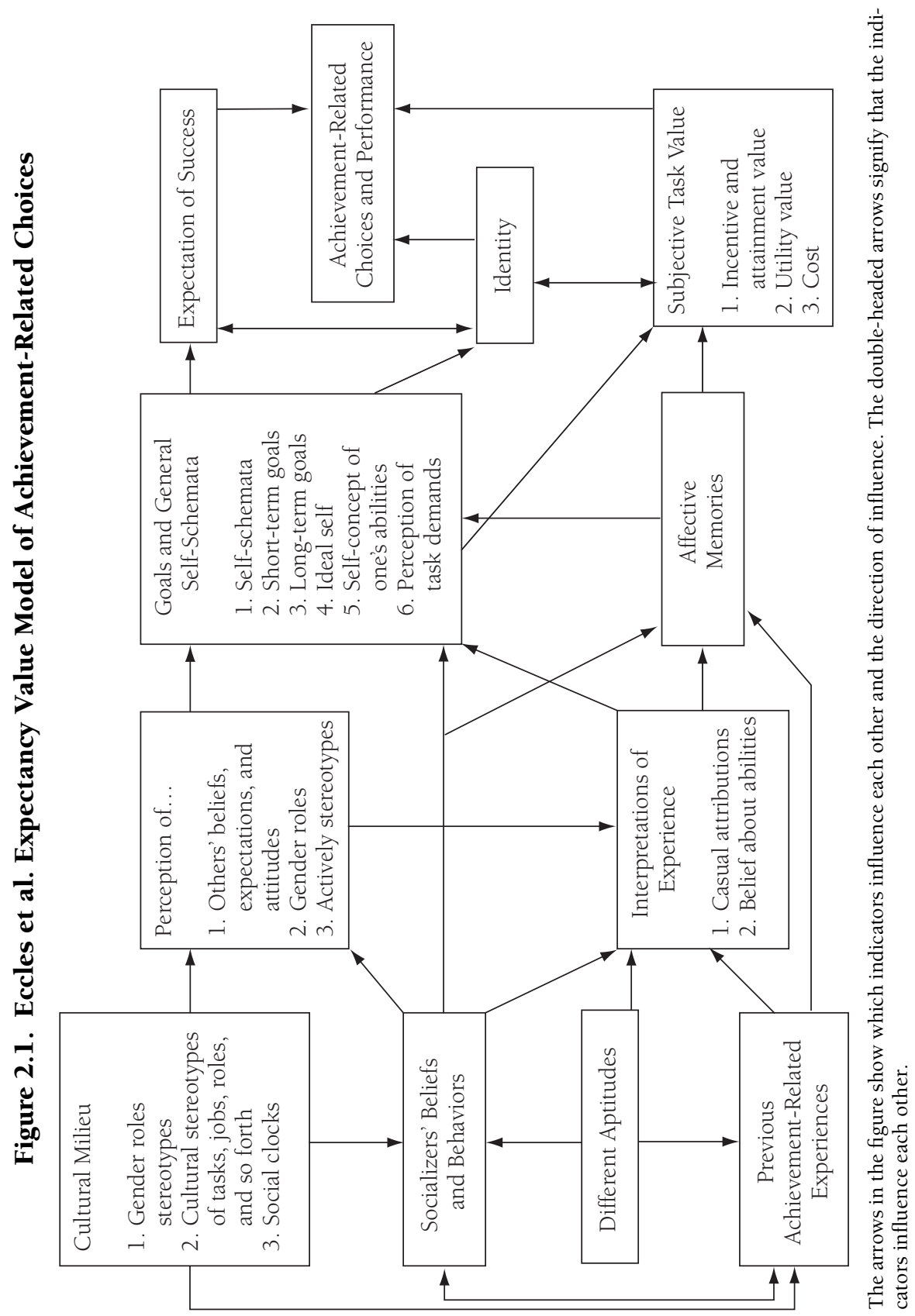


think they can master and that has high task value for them. Expectations for success (domain-specific personal efficacy) depend on both the confidence that individuals have in their various intellectual abilities and the individuals' estimations of the difficulty of the options they are considering. Our research has led us to believe that these self- and task-related beliefs are shaped over time by experiences with the related school subjects and activities and individuals' subjective interpretation of these experiences (for example, whether the person thinks that her or his prior successes reflect high ability or lots of hard work, and if the latter, whether it will take even more work to continue to be successful).

We have also come to believe that the subjective task value of various majors is influenced by several factors. For example, does the person enjoy doing the related school work? Is this major seen as instrumental in meeting the individual's long- or short-range goals? Have the individual's parents, counselors, friends, or romantic partners encouraged or discouraged the individual from selecting this major? Does taking the major interfere with other more valued options because of the amount of work needed to be successful in either the major or future professions linked to the major?

We grouped these aspects of subjective task value into four broad categories: interest value (the enjoyment one gets from engaging in the task or activity), utility value (the instrumental value of the task or activity for helping to fulfill another short- or long-range goal), attainment value (the link between the task and one's sense of self and identity), and cost (defined in terms of either what may be given up by making a specific choice or the negative experiences associated with a particular choice). Given the salience of gender and other group differences in the chapters in this volume, I say a bit more about the last three of these categories because I see them as directly linked to the socialization processes associated with both gender and ethnicity.

My colleagues and I have argued that the socialization processes linked to gender and ethnic roles are likely to influence both short- and long-term goals and the characteristics and values most closely linked to core identities (Eccles, 1993, 1994; Jacobs and Eccles, 1992). For example, gender role socialization is likely to lead to gender differences in the kinds of work one would like to do as an adult: females should be more likely than males to want to work at occupations that help others and fit well into the family role plans. Males should be more likely than females to want future occupations that pay very well and provide opportunities to become famous (see Eccles and others, 1998, and Ruble and Martin, 1998, for reviews of evidence supporting these hypotheses; see Eccles and Vida, 2003, for empirical support). There is also evidence that males are somewhat more interested than females in activities and jobs related to manipulating physical objects and abstract concepts, while females are more interested in activities and jobs related to people and social interactions. These differences are likely to influence the types of jobs that appeal to male and female adolescents. If so, then the 
utility value and attainment value of various high school courses and college majors should also differ on average by gender, precisely because these courses and majors are linked directly to adult occupational choices.

Similarly, the perceived cost of different high school courses and college majors should vary by gender due to the relative importance attached to various options. The cost may also vary by gender due to differences in such emotional costs as math anxiety and the fear of rejection for making nontraditional choices (see Eccles and others, 1998). Whether similar processes are linked to ethnic roles has yet to be fully investigated.

Three features of our approach that are not well captured by the static model depicted in Figure 2.1 are particularly important for understanding individual, as well as gender and other group, differences in the types of educational and occupational choices represented in the chapters that follow. First, we are interested in both conscious and nonconscious achievementrelated behavioral choices. Although the language we use to describe the various components makes it seem that we are talking about quite conscious processes, this is not our intention. We believe that the conscious and nonconscious choices people make about how to spend their time and effort lead, over time, to marked differences between groups and individuals in lifelong achievement-related patterns. We also believe, however, that these choices are heavily influenced by socialization pressures and cultural norms.

Second, we are interested in what becomes part of an individual's perception of viable options. Although individuals choose from among several options, they do not actively consider the full range of objectively available options. Many options are never considered because the individual is either unaware of their existence or has little opportunity or encouragement to really think about a wide range of alternatives. Other options are not seriously considered because the individual has inaccurate information regarding either the option itself or the individual's potential for achieving the option. For example, young people often have inaccurate information regarding the full range of activities associated with various career choices or inaccurate information regarding the financial assistance available for advanced educational training. Yet they make decisions about which occupations to pursue and then select courses in high school that they believe are important for getting into college and majoring in the subject most directly linked to their career aspirations. Too often these choices are based on inaccurate or insufficient information. Finally, many options may not be seriously considered because the individual does not believe that a particular choice fits well with his or her gender role or other social role schemas. Again inaccurate information about what occupations are actually like can lead to premature elimination of quite viable career options. For example, a young woman with excellent math skills may reject the possibility of becoming an engineer or a computer scientist because she has a limited view of what engineers and computer scientists actually do. She may stereotype engineers as nerds or as folks who focus 
on mechanical tasks with little direct human relevance, when in fact, many engineers work directly on problems related to pressing human needs. If so, she may well select herself, or be encouraged to select herself, out of a profession that she might both enjoy and find quite compatible with her life goals and values. As a culture, we do a poor job of providing information to our children and adolescents about occupations. As a consequence, they must rely on media portrayals and happenstance career counseling from their parents, mentors, and friends. Such portrayals are often quite gender and ethnically stereotyped.

Third, we assume that educational and occupational decisions are made within a complex social reality. For example, the decision to major in biology rather than computer science or engineering is made within the context of a complex social reality that presents each individual with a wide variety of choices, each of which has both immediate and long-range consequences that map in complex ways onto the full range of determinants of subjective task value. Furthermore, many options have both positive and negative components. For example, the decision to enroll in an advanced math course in high school is typically made in the context of other important daily life decisions and long-term life decisions, such as whether to take an advanced English course to study literature one enjoys or to take a second foreign language course to aid in one's future travel plans, or to take a course with one's best friend or romantic partner in order to have an intellectual activity to share, or to take less demanding courses in order to spend more time enjoying the social aspects of one's senior year. Similarly, the decision to major in computer science or engineering versus something else is made in the context of a wide range of options and life demands during the college years. The critical issues in our view are the relative personal value of each option and the individual's assessment of his or her relative abilities and potential at the time the decision is being made. In addition, having narrowed the field to those options about which one feels confident about succeeding, we assume that people will choose the options with the highest personal value. Thus, it is the hierarchy of subjective task values and expectations for success that matters rather than the absolute values of both of these belief systems that are attached to the options under consideration. This feature of our approach makes within-person comparisons much more relevant to understanding an individual's decisions than between-group mean-level comparisons. Unfortunately, very little work has taken such a pattern-centered approach.

Consider two high school students: Susan and Wendy. Both young women enjoy mathematics and physical science and have always done very well in these subjects, as well as in their other school subjects. Both have been identified as gifted in mathematics and have been offered the opportunity to participate in an accelerated math program at the local college during their senior year. Wendy hopes to major in communications when she gets to college and has also been offered the opportunity to work part time 
at the local television news station doing odd jobs and some copyediting. Susan hopes to major in computer science in college and plans a career as a research scientist designing educational software. Taking the accelerated math course involves driving to and from the college. Since the course is scheduled for the last period of the day, it will take the last two periods of the day as well as one hour of after-school time to take the course.

What will the young women do? In all likelihood, Susan will enroll in the program because she both likes math and thinks that the effort required to master the material is important for her long-range career goals. Wendy's decision is more complex. She may want to take the class but may also think that the time required is too costly, especially given her alternative opportunity to do an apprenticeship at the television station. Whether she takes the college course will depend in part on the advice she gets from her counselors, family, and friends. If they stress the importance of the math course, then its subjective worth is likely to increase. If its subjective worth increases sufficiently to outweigh its subjective cost, then Wendy will likely take the course despite its cost in time and effort. Studying these types of subtle processes is difficult with individual- and group-difference-oriented variable-centered approaches.

In summary, as outlined in Figure 2.1, my colleagues and I assume that educational and occupational choices (as well as other achievement-related leisure-time choices) are guided by:

Expectations for success on (sense of personal efficacy at) the various options, as well as one's sense of competence for various tasks

The relation of the options to one's short- and long-range goals, core personal and social identities, and basic psychological needs

The individual's culturally based role schemas, such as those linked to gender, social class, religious group, and ethnic group

The potential cost of investing time in one activity rather than another

We assume that all of these psychological variables are influenced by one's experiences and one's interpretation of these experiences, cultural norms, and behaviors and goals of one's socializers and peers.

The chapters in this issue relate directly to several of the components of the Eccles et al. Expectancy Value Model. In Chapter Three, Helen Watt focuses on explaining gender and individual differences in high school course mathematics enrollment patterns. She used a sample of Australian secondary school students and predicted the difficulty level of the students' math curricular track. She controlled for actual achievement levels in her analyses, letting us look at the unique contribution of ability self-concepts and interest value to course enrollment decisions independent of actual math ability level. This study provides quite strong support for the Expectancy Value Model at both the individual and group levels. Sandra Simpkins and Pamela Davis-Kean used a person-centered approach in Chapter Four 
to investigate the joint predictive influence of ninth-grade ability selfconcepts and subjective task value (defined in terms of both enjoyment and perceived importance) on high school math and science course enrollment decisions and career plans, controlling for elementary school teachers' reports of the children's math ability and talent. They focused on gender differences as well and controlled for actual ability levels in all of their analyses. Beginning with children in junior high school, Miriam Linver and Pamela Davis-Kean in Chapter Five investigated the predictors of girls' and boys' math-related performance and interest and ability self-concepts through the secondary school years. They focused on gender differences in combination with math ability curricular track. Finally, Nicole Zarrett and Oksana Malanchuk in Chapter Six examine gender and race differences in young adults' decisions to pursue careers in information technology (IT). They used high school math ability self-concepts and subjective task value, educational expectations, and perceptions related to likely future race and gender discrimination, as well as young adult computer ability self-concepts and enjoyment, support from others, and general attitudes toward computers to predict young adults' desires to pursue careers in IT.

Together these chapters move our understanding of how the various components in the Eccles et al. Expectancy Value Model of AchievementRelated Choice work together with one domain to explain individual and group differences in decisions related to that domain. First, they go beyond just examining gender differences in math and science course choices and career aspirations to address the critical role that ability self-concepts play in such choices. Second, these chapters highlight the importance of subjective task values and consider the circumstances under which task values contribute to choices and aspirations. Finally, they remind us of the importance of strong social supports for difficult achievement choices by measuring the contributions of parents, other adults, and friends to course and achievement choices.

\section{References}

Eccles, J. S. "Gender Roles and Women's Achievement-Related Decisions." Psychology of Women Quarterly, 1987, 11, 135-172.

Eccles, J. S. "School and Family Effects on the Ontogeny of Children's Interests, SelfPerceptions, and Activity Choice." In J. Jacobs (ed.), Nebraska Symposium on Motivation, 1992: Developmental Perspectives on Motivation. Lincoln: University of Nebraska Press, 1993.

Eccles, J. S. "Understanding Women's Educational and Occupational Choices: Applying the Eccles et al. Model of Achievement-Related Choices." Psychology of Women Quarterly, 1994, 18, 585-609.

Eccles, J. S., and Vida, M. "Predicting Gender and Individual Differences in College Major, Career Aspirations, and Career Choice." Paper presented at the biennial meeting of the Society for Research on Child Development, Tampa, Fla., Mar. 2003.

Eccles, J. S., Wigfield, A., and Schiefele, U. "Motivation." In W. Damon (series ed.) and N. Eisenberg (vol. ed.), Handbook of Child Psychology: Vol. 3. Social, Emotional, and Personality Development. Hoboken, N.J.: Wiley, 1998. 
Eccles (Parsons), J., and others. "Expectancies, Values, and Academic Behaviors." In J. T. Spence (ed.), Achievement and Achievement Motivation. New York: Freeman, 1983.

Jacobs, J. E., and Eccles, J. S. "The Impact of Mothers' Gender-Role Stereotypic Beliefs on Mothers' and Children's Ability Perceptions." Journal of Personality and Social Psychology, 1992, 63, 932-944.

Ruble, D., and Martin, C. "Gender Development." In W. Damon (series ed.) and N. Eisenberg (vol. ed.), Handbook of Child Psychology: Vol. 3. Social, Emotional, and Personality Development. Hoboken, N.J.: Wiley, 1998.

JACQUELYNNE S. ECCLES is Wilbert McKeachie Collegiate Professor of Psychology, Women's Studies, and Education, as well as a research scientist, at the Institute for Social Research at the University of Michigan. 